\title{
Assessing African American Women Engineers' Workplace Sentiment within the AI Field
}

Schenita Floyd, University of North Texas, USA

\begin{abstract}
Artificial intelligence (Al) has infiltrated every industry and every aspect of our society. Business leaders have seen the shift Al has created and they are reacting swiftly to stay competitive. They are investing heavily in Al and hiring engineers and other technical professionals to capitalize on Al-based innovations.

Engineers are problem solvers, innovators, and at the forefront of Al technologies; their daily jobs require the consumption of an enormous amount of information to solve problems, enhance existing products, or create new products. Engineering positions require extensive interaction with peers, experts, and other experienced engineers in a male-dominated field. Male dominance causes many women engineers to experience more biases and challenges than their male colleagues, especially minority women engineers. As Al infiltrates our society, will the challenges faced by minority women engineers subside or increase and will they participate in and drive innovations using Al?

The purpose of this research paper is to assess the workplace sentiment of African American women engineers in the Al field. To assess African American women engineers' workplace experiences within the Al field, machine learning text analysis was conducted on data extracted from Twitter. The practical implications of this research highlight African American women engineers' perspectives and experiences, encourages African American women in engineering, and inspires future engineers in Al related careers.
\end{abstract}

Keywords: African American; artificial intelligence; Black Twitter; women engineers; workplace learning

Publication Type: research article

\section{Introduction}

0 ur society is making technological advances at a rapid speed, with innovations in artificial intelligence (Al) as the catalyst. Businesses invest in Al to stay competitive and to improve their revenue. Al does not require a huge investment, but does require human knowledge and expertise. Engineers, data scientists, mathematicians, and other science-related, technical professionals have the skillset and expertise businesses need. Unfortunately, the number of technical professionals in the U.S. is not enough to meet the demands of the country or to support Al innovation.

Science, technology, engineering, and mathematics (STEM) programs have helped increase the number of students majoring in technical fields by encouraging students to explore their interests

The International Journal of Information, Diversity, \& Inclusion, 5(5), 2021

ISSN 2574-3430, https://jps.library.utoronto.ca/index.php/ijidi

DOI: $10.33137 /$ ijidi.v5i5.34765 
in math and the sciences at an early age. Fogg-Rogers et al. (2017) illustrate the importance of women in STEM by helping to motivate future generations of girls, and other underrepresented minorities, to be interested in STEM fields. Fogg-Rogers (2017) stated that "girls need to see women performing STEM activities successfully in order to believe that STEM is for them" ( $p$. 199). Additionally, Fogg-Rogers (2017) argued that such engagement not only helps girls, but also helps fellow peers succeed in their career endeavors. STEM promotion not only supports young African American girls' dream of STEM careers, but it benefits the overall community of African American women. For example, Oh and Lewis (2011) explain that the high wages in STEM careers could help narrow pay inequality. Oh and Lewis (2011) argued that, while white men have dominated STEM careers (which have higher pay), if more women and cultural minorities move into these fields, their presence will increase pay equality.

Despite the success of STEM programs in higher education, retention of technical professionals once they are in the workplace can be difficult due to socio-cultural inequities often exhibited in U.S. STEM workplace settings (Funk \& Parker, 2018). African American women engineers face challenges in the workplace such as sexism, racism, biases, and isolation. These challenges are magnified in technical careers due to a lack of diversity. Morris (2016) notes that women only make up $18 \%$ of all engineers in the U.S. and organizations are seeking to improve diversity to help push innovation. A spokesperson for the Society of Women Engineers was quoted in Morris's (2016) article conveying the point that "diversity fuels innovation, so having multiple perspectives and people of different backgrounds, that's what's going to make organizations successful" (para. 12).

Several studies have explored African American women's challenging experiences in the workplace and how they cope. This study will focus on ways in which African American women engineers within the Al field use social media to cope with challenges experienced at their workplaces. It is crucial to assess African American women engineers' workplace challenges within the Al field for several reasons. First, Al is impacting all our lives, whether we know it or not, and the Al field must represent the people it is affecting. Diversity helps the Al field build innovative products that avoid biases and exclusions of groups of people not represented in the Al industry. Additionally, if organizations address the concerns of African American women engineers who are in the Al field, it will help women to stay in the field, build a diverse pipeline of Al leaders, and help decrease the pay gap for women and the African American community. The purpose of this research is to analyze the workplace sentiment of African American women engineers in Al technology fields. Sentiment analysis, which is sometimes called opinion mining, classifies opinionated user-generated data that has been captured from social media and other platforms to determine the polarity (positive, neutral, or negative) of the data (Varathan et al., 2017). A focus on discourse about workplace concerns and experiences as a specificity of sentiment analysis is why I employ the phrase "workplace sentiment."

To gather the data, machine learning text analysis was conducted using tweets/posts from Twitter, collected over a period of seven days, for a total of 189 hours to document and assess African American women's workplace sentiment in the Al field. Twitter data was analyzed to address the following questions:

- What issues do African American women engineers discuss about Al on Twitter?

- What is the workplace sentiment of the discussions by African American women engineers on Al?

The International Journal of Information, Diversity, \& Inclusion, 5(5), 2021

ISSN 2574-3430, jps.library.utoronto.ca/index.php/ijidi/index

DOI: $10.33137 /$ ijidi.v5i5.34765 
The practical implications of this research study will highlight African American women engineers' perspectives and experiences, encourage African American women in engineering careers, and inspire future engineers in Al related careers.

\section{Review of the Literature}

A review of the literature revealed similar studies on workplace concerns of African American women engineers and other STEM professionals, but not specifically addressing these concerns within the Al field using data from Twitter. Pinckney et al. (2018) described a framework using Twitter which they explained to be a valuable technique for expanding the discourse of African Americans on social media platforms. Other researchers provided theories (e.g., critical race theory and demand-control theory) on coping methods or dealing with race-related issues (Watkins \& Mensah, 2019; Linnabery et al., 2014; Hall et al., 2012; Dickens \& Chavez, 2018). The coping methods they found most effective centered around self-identity and circles of support.

There were studies on the importance of promoting STEM to enhance the number of women engineers (Fogg-Rogers et al., 2017; Oh \& Lewis, 2011; Rice \& Alfred, 2014). Several studies discussed how to succeed as an African American engineer and the barriers faced by African American women in the workplace (Rice \& Alfred, 2014; Dickens \& Chavez, 2018; Linnabery et al., 2014). Some studies discussed how African American women cope with workplace stressors (Hall et al., 2012; Dickens \& Chavez, 2018; Linnabery et al., 2014). Identifying helpful coping methods, promoting STEM, and showcasing how to succeed are still pertinent support resources for African American women engineers, despite the popularity of Twitter. Nonetheless, Twitter does alleviate the geographical constraints when building support circles and finding ways to develop self-identity. Twitter is the social media platform of choice for African American women to discuss social, political, and professional issues (Maragh, 2016; Sharma, 2013; Harris \& Coleman, 2018; Tull et al., 2017). However, the literature did not include studies exploring any intersectionality between all three areas: Al, Twitter, and African American women engineers.

\section{Related Theories and Frameworks}

Watkins and Mensah (2019) employed critical race theory (CRT) to narrate the everyday life of an African American engineering student who started undergraduate studies at one university and then matriculated to other universities for her master's and doctoral degrees. The authors explained how CRT is a counter-storytelling method that allows the engineer to articulate her experiences to be accepted and recognized, while challenging the stereotypes and enlightening readers to her truth. In the narrative, Watkins and Mensah (2019) identified the obstacles the engineering student faced which included isolation and challenges in finding peer support. They expressed the importance of relationships when trying to overcome race-related problems within organizations or groups.

Linnabery et al. (2014) utilized the demand-control theory to study career obstacles faced by African American women. Linnabery et al. (2014) described the demand-control theory as a tool to confront emotional job pressure by balancing one's sphere of control with the circumstances of job demands. They explained that their research was the first study to use demand-control theory to examine African American women's experiences in the workplace. They argued that African American women experiences differ from white women experiences because African Americans experience higher workload and conflicts. Linnabery et al. (2014) noted unique job demands for African Americans, such as racism, racial biases, and lack of resources which were

The International Journal of Information, Diversity, \& Inclusion, 5(5), 2021

ISSN 2574-3430, jps.library.utoronto.ca/index.php/ijidi/index

DOI: $10.33137 /$ ijidi.v5i5.34765 
demands white women did not experience. Career development opportunities, lower salaries, and access to resources were other noted challenges. Linnabery et al. (2014) suggested the use of the demand-control theory to examine how to lower African American women's stresses and strengthen their sphere of control in the workplace. Of course, workplace dynamics that are out of African American women's control exist because such undercurrents are threaded within the context of institutional racism and are thus meted out unchecked. Behaviors projected from (un)conscious racial biases, microaggressions expressed in response to one's skin color, hair texture, or any other erroneous perceived notions, are too often sanctioned by the established influence of institutional racism. In those cases, African American women's experiences vastly differ from what white women experience.

Critical Technocultural Discourse Analysis (CTDA) is a conceptual framework used to study African American women from an innovative approach with Twitter. CTDA looks at the relationship of race in the digital age (Pinckney et al., 2018). Pinckney et. al (2018) used CTDA to investigate how this framework provides the flexibility to innovatively research ways in which users participated in online discourse via smartphones and other types of media devices. This study revealed the importance of researchers being more innovative when collecting data from social media. Identifying similar concepts as Pinckney et. al (2018) within my own research questions, I decided to employ Twitter as my digital platform for fieldwork, and CTDA as the framework to examine African American women engineers' workplace sentiment.

\section{Challenges and Barriers in the Workplace}

African American women engineers endure some specific obstacles in the workplace. These obstacles impact their normal job functions and may halt or change momentum in one's career path until the obstacle or barrier is removed. For example, Oh and Lewis (2011) discuss how organizational climates and dynamics could result in African American women engineers feeling discomfort and isolation. Watkins and Mensah (2019) agree that social and emotional isolation stemmed from racism is a barrier that many African American women engineers face in the workplace. Another challenge many African American women encounter during their careers is unemployment or underemployment. Cross (2014) confirms that African Americans have the highest rate of unemployment within the field of engineering. If African American women engineers are employed, and succeed in their careers, they typically face other challenges. For example, Linnabery et al. (2014) argue that African American women experience job-family strain and lack of career and life satisfaction. Whereas Parker (2002) states that African American women who experience conflicts with their white male colleagues are ignored or have their ideas overlooked.

Despite the many barriers faced by African American women engineers, Fogg-Rogers et al. (2017) recommend that leadership endorsement could help remove barriers and promote self-efficacy. Oh and Lewis (2011) suggest that peer support from friends, family, community, and other relationships can alleviate the barriers and challenges African American women engineers face. Linnabery et al. (2014) agree with the importance of support (be it collegial, familial, community-oriented, etc.), especially social support which can provide a means for self-care.

\section{Coping in the Workplace}

For African American women engineers to function properly in the workplace, they have to figure out how to cope with the challenges and barriers they encounter. Linnabery et al. (2014) explain

The International Journal of Information, Diversity, \& Inclusion, 5(5), 2021

ISSN 2574-3430, jps.library.utoronto.ca/index.php/ijidi/index

DOI: $10.33137 /$ ijidi.v5i5.34765 
that learning to cope helps build strength. They identify techniques to help with coping which includes valuing yourself by connecting with ancestors who came before you, asking for support from others, and praying to deal with stress. Hall et al. (2012) agree with spirituality as a coping technique and they also suggest thinking positively, improving social skills, and interacting with friends and family. Finally, Dickens and Chavez (2018) recommend identity shifting to cope with stress, but they admit this technique could have drawbacks. The drawbacks tend to outweigh the success women receive through identity shifting. Given the drawbacks of identity shifting and finding support, Twitter can fill the gap as an alternative to these coping techniques. Today, African American women share their challenges on Twitter. The discourse on Twitter among African American women gives context to understand how African American women feel and cope with workplace stressors. Other African-descent women facing similar challenges in the workplace can see commonalities and share their feelings and stories on Twitter. These shared experiences on Twitter simulate some of the coping techniques recommended in the literature to succeed in the workplace.

\section{Success in the Workplace}

Success in the workplace requires the ability to overcome barriers and learn to cope while staying strong. The balance for African American women engineers can be a heavy burden and can lead to women leaving the engineering field. Rice and Alfred (2014) argue for support systems throughout the entire pipeline to encourage women to stay in the field and succeed. Support systems are common in higher education, but they need to be in the field at all levels to encourage and support African American women engineers and other underrepresented groups. The implication and rewards of support systems in organizations promote diversity and innovation organizations seek. Rice and Alfred (2014) recommend African American women engineers seek a peer community as their main source of daily support.

\section{Black Twitter and Blacktags}

In today's digital age, social media provides the perfect method to build a community of support. There are many social media platforms available; however, Twitter seems to be the platform of choice for African American social and cultural discourse. Maragh (2016) reported through a 2015 Pew research study, that among African American internet users, 28\% were Twitter users. Punctuating the point that Twitter is a consistent place of discourse for African Americans online, Pew Research Center's 2021 social media factsheet reports that 29\% of African Americans use Twitter (Pew, 2021).

Several studies have been conducted on the phenomenon of Black Twitter and Blacktags. Sharma (2013) describes the phenomenon and defines Blacktags as "a particular type of hashtag associated with Black Twitter users (mainly African-Americans), because the tag itself and/or its associated content appears to connote 'Black' vernacular expression in the form of humor and social commentary" (p. 48). Sharma (2013) lists famous hashtags and explains how they have gained popularity by spreading to other media outlets to heighten awareness and visibility on a particular subject.

Twitter has been used for political awareness, racial discrimination awareness, and social activism through the hashtag \#BlackLivesMatter. Tull et al. (2017) describe how Twitter was used to devise solutions to improve diversity in technology fields. Tull et al. (2017) explains how, in their research, they tracked tweets over a two-day period by using \#ThinkBigDiversity. Many

The International Journal of Information, Diversity, \& Inclusion, 5(5), 2021

ISSN 2574-3430, jps.library.utoronto.ca/index.php/ijidi/index

DOI: $10.33137 /$ ijidi.v5i5.34765 
other hashtags have emerged to express the issues and sentiments technical professionals encounter in everyday life. Through analysis and exploration, more solutions to issues discussed in the Twitter discourse could be identified, as with the \#ThinkBigDiversity campaign.

\section{Methodology}

This study is an exploratory research study using data extracted from Twitter to perform a sentiment analysis. The framework incorporated in this study is the CTDA framework created by André L. Brock (2016), a pioneer in the scholarly study of the Black experience on Twitter. As noted by Pinckney et al. (2018), Brock's CTDA framework suggests focusing on a single online topic to recognize the relationship between race and social justice as discussed on new digital technologies and platforms (Pinckney et al., 2018). CTDA includes three main components: multimodal data, interface analysis, and critical discourse. Multimodal Twitter data is used in this study to analyze Black women engineer's workplace sentiment through their discourse on Twitter. Each step of CTDA is followed as illustrated by Brock (2016), who is a proponent of using Twitter with the framework. Brock (2016) describes Twitter "as a service (artifact), as interface and mechanics (practice), and as the discourses of its users and observers (belief)" (p. 1024).

\section{Multimodal Data}

Twitter data was collected over a 24 hour, seven-day period totaling 189 hours using hashtags promoted by African American women engineers and other African American women in the STEM professions. The seven-day period was selected to coincide with the Women in Science Week held from February 9-February 16, 2020, which included the International Day of Women and Girls in Science that occurred on February 11, 2020.

\section{Interface Analysis}

The data collected was captured using Twitter API (application programming interface) for developers and researchers. Text mining $\mathrm{R}$ packages helped to clean the data removing extra tags, duplicate tweets, emojis, and stop words. Once the data was cleaned, a machine learning algorithm was run on the data to obtain the overall sentiment in the discussions. Machine learning algorithms are an appropriate method to analyze a large corpus of words versus a manual method that could be subject to human error. The machine learning sentiment algorithm analyzes the number of positive and negative words in the tweets. Next, the algorithm outputs a sentiment histogram and text files for the researcher to review what was coded as positive and what was coded as negative. The positive and negative text files contain detailed scoring data to verify the results of the algorithm. The text files are beneficial for reviewing the raw data in a clean format and explaining how the algorithm produced the final results in the sentiment histogram.

\section{Critical Discourse}

Hashtags are used throughout social media to help categorize and bring attention to a particular topic. Seven hashtags selected for this study are promoted by technical non-profit organizations and African American technical professionals who participate in these organizations. Three of the hashtags are Blacktags used by Black Twitter to discuss topics African American technical professional women face: \#BlackInAl, \#BlackTechTwitter, and \#BlackWomenAtWork. Blacktags allow African Americans to share their workplace experiences amongst each other when they feel isolated or marginalized. Pinckney et al. (2018) posits that "among Black users, if they do

The International Journal of Information, Diversity, \& Inclusion, 5(5), 2021

ISSN 2574-3430, jps.library.utoronto.ca/index.php/ijidi/index

DOI: $10.33137 /$ ijidi.v5i5.34765 
not matter, then they will matter at least among those same Black users" (p. 284). The four other hashtags selected are used by African American women but are not consider Blacktags: \#WomenEngineers, \#WomenInAI, \#StemWomen, and \#WomenInScience.

\section{Results}

Over 6,200 tweets were collected during Women in Science week held from February 9-16, 2020. Most of the tweets were from \#WomenInScience mainly because it was promoted heavily during the Women in Science events around the world. There were over 30 tweets from \#WomenInScience that referenced the February 11th International Day of Women and Girls in Science. Their tweets celebrated pioneers in the field and others advocated for equal pay. A couple of tweets supported Australia's Women in STEM Decadal Plan, which works toward retaining women in STEM and achieving gender equity.

The second highest number of tweets was from the Blacktag \#BlackTechTwitter with over 500 tweets. There were 30 tweets from \#BlackTechTwitter that directly referenced women and 12 tweets that referenced engineers. One woman engineer celebrated her first-year anniversary as a Software Engineer building new apps. Table 1 shows the total tweets of each of the hashtags extracted from Twitter API.

Table 1. Technical Twitter Hashtags

\begin{tabular}{ll}
\hline Hashtag & Number of Tweets during the 7-day period \\
\hline \#BlacklnAl & 3 \\
\#BlackTechTwitter & 513 \\
\#BlackWomenAtWork & 14 \\
\#WomenEngineers & 33 \\
\#WomeninAl & 24 \\
\#StemWomen & 154 \\
\#WomenInScience & 5478 \\
\hline
\end{tabular}

Table 2 displays a sample of the tweets used to determine the sentiment. The tweets highlight African American women engineers' issues with gender bias and lack of diversity in the workplace. There were also tweets that offered professional encouragement and job opportunity information.

Next, the 6,219 tweets were cleaned using the R packages to remove extra tags, duplicates, emojis, and stop words. After cleaning the data, a sentiment analysis algorithm was run on the data to obtain the overall sentiment in the discussions. The sentiment analysis results in Figure 1 show that most of the tweets were positive. Since the number of tweets for \#WomenInScience was greater than the other hashtags, \#WomenInScience was analyzed separately to ensure it did not dominate the sentiment of the other hashtags.

The International Journal of Information, Diversity, \& Inclusion, 5(5), 2021

ISSN 2574-3430, jps.library.utoronto.ca/index.php/ijidi/index

DOI: $10.33137 /$ ijidi.v5i5.34765 
Table 2. Twitter Hashtag Tweets

\begin{tabular}{|c|c|c|}
\hline Hashtag & Tweets & \\
\hline \#BlacklnAl & $\begin{array}{l}\bullet \\
\bullet \\
\bullet\end{array}$ & $\begin{array}{l}\text { tbt to a fun night and very interesting conversation } \\
\text { about the impacts of \#Al on diverse communities with } \\
\text { leaders } \\
\text { The current data on the state of gender diversity in Al } \\
\text { is dire.... The state of racial diversity is worse. } \\
\text { The stickers table at \#AAAI20 Pronouns stickers } \\
\text { \#QueerinAl, \#BlackinAl \#LatinxinAl.InIn@RealAAAl } \\
\text { \#phdchat }\end{array}$ \\
\hline \#BlackTechTwitter & & $\begin{array}{l}\text { Possible Job Opportunity } \\
\text { Check out Hacking With The Homies Developers } \\
\text { Conference } \\
\text { Does the terminology slave and master in CS bother } \\
\text { anyone else? }\end{array}$ \\
\hline \#BlackWomenAtWork & & $\begin{array}{l}\text { Girl, you got this, you can handle it! You are Amazing } \\
\text { This is what a woman in science looks like } \\
\text { Highlights daily challenge of an Al/robot matters to use } \\
\text { gender-sensitive language will impact race }\end{array}$ \\
\hline \#WomenEngineers & & $\begin{array}{l}\text { Celebrating women who've been able to prove } \\
\text { stereotypes wrong that we can't have women pursuing } \\
\text { scientific careers } \\
\text { She's the engineer behind eye-popping invention in } \\
\text { @GM's newest SUVs }\end{array}$ \\
\hline \#WomenInAl & & $\begin{array}{l}\text { There is a significant gender diversity gap in Al research } \\
\text { Make those meaningful connections. Find your tribe. } \\
\text { Help build others. Build those communities. Establish } \\
\text { your com } \\
\text { Really interesting discussion to watch about the issues } \\
\text { with Al }\end{array}$ \\
\hline \#StemWomen & & $\begin{array}{l}\text { Find out more about the \#genderimbalance in \#STEM } \\
\text { and how to remedy it } \\
\text { Love to see more women in science! }\end{array}$ \\
\hline \#WomenInScience & & $\begin{array}{l}\text { Building bridges; breaking barriers - discussion panel on } \\
\text { how to manage a successful career in \#academia } \\
\text { Science cannot afford to only look at half the } \\
\text { population to supply its workforce, we need a diversity } \\
\text { We cannot afford to stay silent in the face of } \\
\text { systematic barriers; long-standing biases that continue } \\
\text { to prevent }\end{array}$ \\
\hline
\end{tabular}

The International Journal of Information, Diversity, \& Inclusion, 5(5), 2021

ISSN 2574-3430, jps.library.utoronto.ca/index.php/ijidi/index

DOI: $10.33137 /$ ijidi.v5i5.34765 


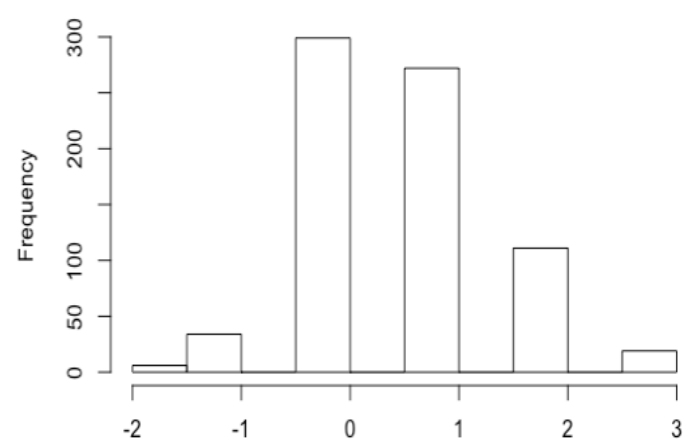

Figure 1. Twitter Hashtag Sentiments. Twitter data (741 tweets) was analyzed to determine the sentiment.

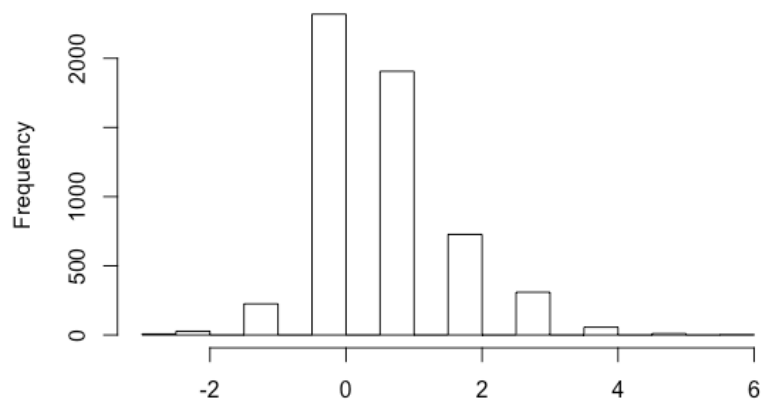

Figure 2. Twitter Hashtags Sentiments: Twitter data (\#WomeninScience) was analyzed to determine the sentiment.

The histograms in Fig. 1 and Fig. 2 show sentiments from Twitter data extracted February 9-16, 2020. The negative coordinates on the left on the $x$-axis are tweets with a negative sentiment. The positive coordinates on the right on the $x$-axis are positive tweets. Frequency on the $y$-axis shows the count of unique words in the corpus of tweets. The first graph, in Fig. 1, includes 741 tweets with an overall positive sentiment to the right. The second graph, in Fig. 2, includes 5478 tweets with an overall positive sentiment.

The results of the data analysis reinforced previous studies on the issues African American women engineers face as the tweets on Twitter amplified the issues with lack of diversity and gender biases in Al. Despite the negative issues African American women face in Al, the tweets on Twitter had a positive sentiment. Tweets were filled with positive words of hope and encouragement for fellow African American women engineers in Al.

\section{Conclusion}

In summary, this research study on African American women engineers' Twitter discourse about workplace sentiment in Al covered a review of the literature on relevant theories and frameworks pertaining to the critical lenses needed to explore nuances in discourse. Additionally, it analyzed

The International Journal of Information, Diversity, \& Inclusion, 5(5), 2021

ISSN 2574-3430, jps. library.utoronto.ca/index.php/ijidi/index

DOI: $10.33137 /$ ijidi.v5i5.34765 
Twitter data from African American women technical professionals to identify their issues and sentiment in the field of $\mathrm{Al}$ and also demonstrated ways that women engineers can use social media to cope with workplace issues and be successful despite barriers faced. The limitations of this study were the sparse data found during the time period selected and not expanding the research to other social media platforms. Expanding the time period and tackling other social media platforms could provide more insight into African American women's workplace sentiment within the field of Al.

The practical implications for African American women engineers and companies committed to retaining women engineers are numerous. Future and current engineers will obtain insight on how to navigate their careers. Companies will learn how to make their environments more open to African American women engineers. Helping African American women engineers helps companies ensure a diverse technical workforce for Al innovation. This study expands both the information science and the African American studies fields by looking at a specific technical profession and exploring ways in which online discourse enhances and supports social navigation of hegemonic workplace environments.

Future studies in this area should collect more data than the limited seven days gathered in this study. While the Twitter API currently has rate and accessibility limits, Twitter is looking to improve their platform for researchers. Twitter API improvements will provide researchers the ability to extract more data to do an extensive thematic analysis, over time, to pinpoint the primary areas companies should focus on to support and retain African American women engineers in their organizations. This study utilized the current standard Twitter API which pulled real-time data over a seven-day period, but future studies could utilize Twitter's new researcher platform or their premium and enterprise licenses to pull historical data for a year (i.e., 2020 with the same hashtags) with less rate restrictions. Future studies could also analyze different hashtags for other marginalized groups (i.e., Women, U.S. Native Americans, or Disabled Veterans) or integrate data from other social media platforms.

\section{References}

Brock, A. (2016). Critical technocultural discourse analysis. New Media \& Society, 20(3), 10121030. https: / /doi.org/10.1177/1461444816677532

Dickens, D. D., \& Chavez, E. L. (2018). Navigating the workplace: The costs and benefits of shifting identities at work among early career US Black women. Sex Roles, 78(11-12), 760-774. https://doi.org/10.1007/s11199-017-0844-x

Cross, K. J. (2014). The impact of African American engineers on contemporary life: Remembering who we are. Black History Bulletin, 77(2), 22-27. https: //www.jstor.org/stable/10.5323/blachistbull.77.2.0022

Fogg-Rogers, L., Sardo, M., \& Boushel, C. (2017). “Robots vs animals”: Establishing a culture of public engagement and female role modeling in engineering higher education. Science Communication, 39(2), 195-220. https://doi.org/10.1177/1075547017696169

Funk, C., \& Parker, K. (2018). Women and men in STEM often at odds over workplace equity:

The International Journal of Information, Diversity, \& Inclusion, 5(5), 2021

ISSN 2574-3430, jps. library.utoronto.ca/index.php/ijidi/index

DOI: $10.33137 /$ ijidi.v5i5.34765 
Perceived inequities are especially common among women in science, technology, engineering and math jobs who work mostly with men. Pew Research Center: Social \& Demographic Trends. https://www.pewresearch.org/social-

trends/2018/01/09/women-and-men-in-stem-often-at-odds-over-workplace-equity/

Hall, J. C., Everett, J. E., \& Hamilton-Mason, J. (2012). Black women talk about workplace stress and how they cope. Journal of Black Studies, 43(2), 207-226. https: //doi.org/10.1177/0021934711413272

Harris, F. L., \& Coleman, L. S. (2018). Trending topics: A cultural analysis of being Mary Jane and Black women's engagement on Twitter. The Black Scholar, 48(1), 43-55. https://doi.org/10.1080/00064246.2018.1402255

Linnabery, E., Stuhlmacher, A. F., \& Towler, A. (2014). From whence cometh their strength: Social support, coping, and well-being of Black women professionals. Cultural Diversity and Ethnic Minority Psychology, 20(4), 541-549. https://doi.org/10.1037/a0037873

Maragh, R. S. (2016). “Our struggles are unequal”: Black women's affective labor between television and Twitter. Journal of Communication Inquiry, 40(4), 351-369. https://doi.org/10.1177/0196859916664082

Morris, C. (2016, October 31). Study underscores bias obstacles for women, minorities in engineering. Diverse Issues in Higher Education, 33(7). https://diverseeducation.com/article/88736/

Oh, S. S., \& Lewis, G. B. (2011). Stemming inequality? Employment and pay of female and minority scientists and engineers. The Social Science Journal, 48(2), 397-403. https://doi.org/10.1016/j.soscij.2010.11.008

Parker, P. S. (2002). Negotiating identity in raced and gendered workplace interactions: The use of strategic communication by African American women senior executives within dominant culture organizations. Communication Quarterly, 50(3-4), 251-268. https://doi.org/10.1080/01463370209385663

Pew Research Center. (2021, April 7). Social media factsheet. https://www.pewresearch.org/internet/fact-sheet/social-media/

Pinckney, H. P., Mowatt, R. A., Outley, C., Brown, A., Floyd, M. F., \& Black, K. L. (2018). Black spaces/white spaces: Black lives, leisure, and life politics. Leisure Sciences, 40(4), 267287. https://doi.org/10.1080/01490400.2018.1454361

Rice, D. N., \& Alfred, M. V. (2014). Personal and structural elements of support for African American female engineers. Journal of STEM Education: Innovations and Research, 15(2). https://www.jstem.org/jstem/index.php/JSTEM/article/view/1843

Sharma, S. (2013). Black Twitter? Racial hashtags, networks and contagion. New Formations, 78, 46-64. https://doi.org/10.3898/NewF.78.02.2013

Tull, R. G., Reed, A. M., Felder, P. P., LGSW, S. H., Williams, D. N., Medina, Y., Lo, A., Aparaka, E. T., \& Ordonez, P. (2017). Hashtag \#ThinkBigDiversity: Social media hacking

The International Journal of Information, Diversity, \& Inclusion, 5(5), 2021

ISSN 2574-3430, jps.library.utoronto.ca/index.php/ijidi/index

DOI: $10.33137 /$ ijidi.v5i5.34765 
activities as hybridized mentoring mechanisms for underrepresented minorities in STEM. Paper presented at the 2017 ASEE Annual Conference \& Exposition, Columbus, Ohio. https://doi.org/10.18260/1-2--28430

Varathan, K. D., Giachanou, A., \& Crestani, F. (2017). Comparative opinion mining: A review. Journal of the Association for Information Science and Technology, 68(4), 811-829. https://doi.org/10.1002/asi.23716

Watkins, S. E., \& Mensah, F. M. (2019). Peer Support and STEM success for one African American female engineer. The Journal of Negro Education, 88(2), 181-193. https://www.jstor.org/stable/10.7709/jnegroeducation.88.2.0181

Schenita Floyd (schenitafloyd@my.unt.edu) is a doctoral candidate at the University of North Texas in Denton where she is pursuing her PhD in Interdisciplinary Information Science with an anticipated graduation date of August 2021. Her concentration is data science, and her research interests include Artificial Intelligence (Al), team collaboration, digital workforce transformation, and the gender pay gap. Schenita has a BS degree in electrical engineering from Texas A\&M University in College Station and she has an MBA in finance from Southeastern University. 